\title{
A contribuiç̧ão das universidades e indústrias do Rio de Janeiro no desenvolvimento de tecnologias de Defesa Nacional
}

\author{
Vitelio Marcos Brustolin*
}

\begin{abstract}
Resumo
Neste artigo defende-se que as tecnologias possuem usos múltiplos, podendo ter emprego civil e militar. Também se comprova, através de documentos oficiais, que o Brasil tem sofrido entraves tecnológicos de nações estrangeiras, tornando vantajoso produzir equipamentos militares em território nacional. Por fim, demonstra-se que o país possui estrutura para produção local de ciência e tecnologias de Defesa e que o Estado do Rio de Janeiro destaca-se nesse contexto. A metodologia utilizada é de análise de recortes da história industrial-militar, além de legislação, documentos e dados oficiais. A pesquisa é parte de tese doutoral produzida na Universidade Federal do Rio de Janeiro e na Universidade Harvard (EUA), com recursos da Capes e da Fundação Lemann.
\end{abstract}

Palavras-chave: Tecnologias de usos múltiplos; Geração de ciência e tecnologia via Defesa Nacional; O complexo militar-industrial-acadêmico no Estado do Rio de Janeiro (Brasil).

\begin{abstract}
This paper argues that technologies have multiple uses, with both civil and military employment. It also demonstrates, through official documents, that Brazil has suffered technological embargoes by foreign nations, making advantageous to produce military devices inside the country. Finally, this study demonstrates that the country has structure to produce locally science and technologies of Defense and that the State of Rio de Janeiro stands out in this context. The methodology used is an analysis of cutouts of the industrial-military history, in addition to legislation, documents and official data. The research is a part of Doctoral Thesis produced at Federal University of Rio de Janeiro (Brazil) and at Harvard University (USA), with funding from Capes and Lemann Foundation.
\end{abstract}

Keywords: Multiple-use technology. Generation of science and technology through National Defense. The military-industrial-academic complex in the state of Rio de Janeiro (Brazil).

\footnotetext{
* Professor Adjunto do Instituto de Estudos Estratégicos (INEST) da Universidade Federal Fluminense (UFF), Fellow e Researcher PhD da Harvard Law School e do Harvard Department of the History of Science, Lemann Fellow. Doutor em Políticas Públicas, Estratégias e Desenvolvimento. E-mail: info@viteliobrustolin.com, website: http://scholar.harvard.edu/brustolin.

Agradecimento aos pesquisadores que tornaram o presente estudo possível: Luiz Martins de Melo (UFRJ), Roberto Mangabeira Unger (Harvard), Peter Louis Galison (Harvard), Cristina de Albuquerque Possas (Fiocruz), Lia Hasenclever (UFRJ).
} 


\section{Introdução}

O Brasil já produziu e ainda produz - em uma escala relativamente menor - inovações militares. Até o final da década de 1980, 90\% dos meios que mobilizavam o Exército eram fabricados em território nacional (Amarante, 2004:27). O regime militar foi encerrado em 1985, numa transição de redemocratização, e os militares passaram a ser subordinados a governantes civis, como é característico nas democracias (Couto, 1999).

No entanto, as transformações políticas e sociais das décadas de 1990 e 2000 trouxeram consigo um desnecessário "quase aniquilamento da base industrial de defesa e uma considerável redução das atividades nos centros de P\&D [Pesquisa e Desenvolvimento] nacionais, notadamente naqueles que constituem a base científico-tecnológico de defesa" (Amarante, 2004:27)

O país vem retomando os investimentos no setor, sobretudo a partir de 2007: ${ }^{1}$

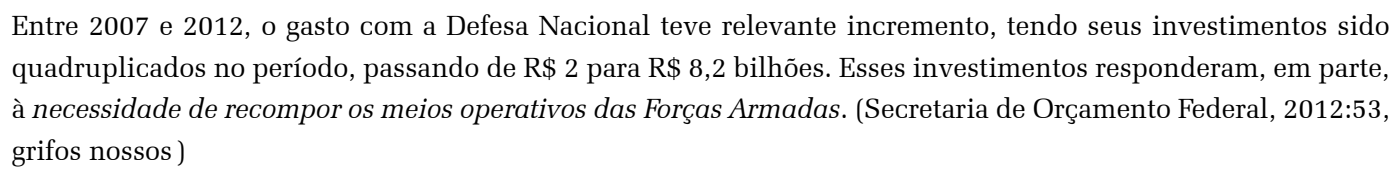
quadruplicados no período, passando de R 2 para R \$ 8,2 bilhões. Esses investimentos responderam, em parte, à necessidade de recompor os meios operativos das Forças Armadas. (Secretaria de Orçamento Federal, 2012:53, grifos nossos )

Cabe salientar que a Defesa Nacional do Brasil é muito mais utilizada para resolver problemas de segurança interna do que para conflitos externos. As suas atribuições estão descritas no Artigo 142 da Constituição Federal: "defesa da Pátria, garantia dos poderes constitucionais e, por iniciativa de qualquer destes, da lei e da ordem” (Brasil, 1988). No entanto, para cumprir tais atribuições, são necessários equipamentos, que podem ser simplesmente comprados no exterior ou terem produção local, auxiliando a desenvolver a ciência, a tecnologia e capacitando a mão de obra nacional nesse processo.

Dados da Associação das Indústrias de Materiais de Defesa e Segurança (ABIMDE) demonstram que esse setor gera, no Brasil, 25 mil empregos diretos, 100 mil indiretos e cerca de US\$ 2,7 bilhões anuais em vendas. As empresas são de alta tecnologia, sendo que 35 delas exportam (20 regularmente), gerando US\$ 1 bilhão anuais em exportações (Moreira, 2011:56). A expectativa de investimentos é de US\$ 100 bilhões nos próximos 20 anos (Defesanet, 31 jan. 2013).

Nesse contexto, o primeiro objetivo do presente artigo é destacar que tecnologias possuem usos múltiplos, podendo ser empregadas tanto por militares, quanto por civis, nas mais diversas aplicações - muitas imprevisíveis no momento de sua idealização.

O segundo objetivo é demonstrar que desenvolver pesquisas e indústrias na área de Defesa é uma necessidade para o Brasil, devido aos entraves tecnológicos provenientes de nações estrangeiras.

O terceiro objetivo é enfatizar que o Brasil - e dentro dele, o Estado do Rio de Janeiro possui estrutura para a geração de tecnologias de Defesa Nacional.

1 DEPARTAMENTO DE PLANEJAMENTO, ORÇAMENTO E FINANÇAS (Ministério da Defesa, Brasil). Execução Orçamentária: Séries Estatísticas, 2000 - 2012. Disponível em: <www.defesa.gov.br/lai/images/despesas/serie_estatistica_1995_2012.pdf > . Acesso em 30 jan. 2014. 


\section{Tecnologias possuem usos múltiplos}

O conceito de "tecnologia de uso dual" tem poucas variações na literatura acadêmica e todas são muito próximas à sintetização de Molas-Gallart: "Eu defino uma tecnologia como de uso dual quando tem aplicações militares e civis, atuais ou potenciais" (Molas-Gallart, 1998:3). ${ }^{2}$ O próprio autor reconhece, todavia, que a definição "dual” é apenas para fins analíticos, já que, em geral, é muito difícil discernir se uma tecnologia terá emprego apenas civil ou militar, podendo, portanto, ser considerada de "usos múltiplos" (Molas-Gallart, 1998:4).

Cardoso cita casos de inovações tecnológicas e conhecimentos militares com emprego civil, desenvolvidos no Brasil:

\section{Tabela 1}

Inovações Militares Desenvolvidas no Brasil com Aplicação Civil

\begin{tabular}{|c|c|}
\hline $1969-1971:$ & $\begin{array}{l}\text { Criação e implantação da EMBRAER. Projetos do IPANEMA e do XAVANTE, base da indústria aeronáutica } \\
\text { brasileira; }\end{array}$ \\
\hline \multirow[t]{3}{*}{ Década de 1970: } & $\begin{array}{l}\text { - Engenhos autopropulsados deram origem aos mísseis, foguetes antigranizo e, mais recentemente, ao } \\
\text { Veículo Lançador de Satélite; }\end{array}$ \\
\hline & $\begin{array}{l}\text { - Viaturas blindadas sobre rodas (Urutu e Cascavel) - suspensão 'boomerang' utilizada, também, em veículos } \\
\text { 'off-road' de emprego civil; }\end{array}$ \\
\hline & $\begin{array}{l}\text { - Sistema PAL-M de TV - projeto desenvolvido no Instituto Militar de Engenharia (IME) visando ao } \\
\text { acompanhamento de operações militares; }\end{array}$ \\
\hline \multirow[t]{2}{*}{ Década de 1980: } & $\begin{array}{l}\text { - Programa Nuclear da Marinha - submarino com propulsão nuclear; enriquecimento de urânio por } \\
\text { ultracentrifugação (tecnologia já dominada). }\end{array}$ \\
\hline & - Programa Nuclear do Exército - tecnologia de reatores; obtenção de grafite com elevado índice de pureza. \\
\hline \multirow[t]{2}{*}{ Década de 1990: } & - Início da pesquisa visando à tecnologia de obtenção de fibra de carbono. \\
\hline & - Irradiação de alimentos. \\
\hline \multirow[t]{13}{*}{ Década de 2000: } & - Novos materiais para pavimentação - argila calcinada (construção de estradas na Amazônia). \\
\hline & - Instalações de biossegurança (Defesa e Saúde). \\
\hline & $\begin{array}{l}\text { - Processamento de sinais de voz e imagem (serviço de inteligência e segurança pública) - desenvolvimento } \\
\text { de sistemas de filtragem para transmissão e reconhecimento de sinais de voz. }\end{array}$ \\
\hline & $\begin{array}{l}\text { - Sistemas de Comunicações - tele-detecção e contramedidas eletrônicas (Segurança Pública, clonagem de } \\
\text { telefones etc.). }\end{array}$ \\
\hline & - Materiais para dispositivos eletrônicos - filmes finos para células solares e detectores de infravermelho. \\
\hline & - Geração elétrica com hidrocinéticos - desenvolvimento de protótipo. \\
\hline & $\begin{array}{l}\text { - Sistema de monitoramento de tropas mecanizadas (defesa e segurança pública) - sistema de } \\
\text { acompanhamento de viaturas via rede rádio em conjunto com sistema de posicionamento global por satélites } \\
\text { (GPS). }\end{array}$ \\
\hline & $\begin{array}{l}\text { - Fontes alternativas de energia a partir de materiais nacionais - desenvolvimento sustentável. Obtenção de } \\
\text { óleo diesel vegetal utilizando como catalisadores novos materiais à base de nióbio. }\end{array}$ \\
\hline & - Segurança da informação - criptografia. \\
\hline & - Cartografia digitalizada. \\
\hline & $\begin{array}{l}\text { - Veículos Aéreos Não Tripulados (VANT) - sistema de reconhecimento e busca, com aplicação na agricultura, } \\
\text { monitoramento de reservas florestais, de fronteiras, etc. }\end{array}$ \\
\hline & $\begin{array}{l}\text { - Pilhas térmicas - para mísseis e, também, para acionamento dos foguetes embarcados em satélites } \\
\text { (correção de órbita). }\end{array}$ \\
\hline & - Veículo híbrido. - Pesquisa de fibra de carbono a partir do piche mesofásico.” \\
\hline
\end{tabular}

Fonte: Elaboração própria com informaçóes de Cardoso (2004:192-195).

Fica claro, na Tabela 1, que tecnologias militares e civis se aproximam e que, com adaptações, podem ser empregadas para ambas as finalidades. Desse modo, confirma-se a assertiva de um dos documentos oficiais norteadores do Brasil, a Estratégia Nacional de

2 "I define a technology as dual use when it has current or potential military and civilian applications.” Disponível em: <www.cops.ac.uk/pdf/cpn55. pdf > . Acesso em: 30 jan. 2014. 
Defesa: “O objetivo será fomentar o desenvolvimento de um complexo militar universitárioempresarial capaz de atuar na fronteira de tecnologias que terão quase sempre utilidade dual, militar e civil” (Brasil, 2013:1).

De fato, é difícil prever, sobretudo no início de uma pesquisa científica ou projeto tecnológico, quais serão todos os seus possíveis usos. $\mathrm{O}$ antigo sonho do homem de criar mecanismos para voar, por exemplo, que teve origem absolutamente civil, encontrou farto uso militar, já durante a Primeira Guerra Mundial, quando o bombardeio aéreo passou a ser empregado para combater trincheiras. Da mesma forma, o desenvolvimento de computadores eletrônicos, do GPS, das fibras óticas, do telefone celular, do micro-ondas, dos aviões à jato e da Internet - entre muitas outras tecnologias -, que tiveram origem militar, revolucionaram o mercado civil (Smith, 1985:4). Há pesquisas, por outro lado, que são ainda mais imprevisíveis, como no caso das biológicas: ao mesmo tempo em que o estudo de determinada bactéria ou vírus pode salvar milhares de vidas de uma epidemia, também pode ser empregado em guerras. A questão, evidentemente, é de como o homem emprega o seu conhecimento, invenções e descobertas.

Complementarmente, também a história industrial do Brasil demonstra que tecnologias possuem capacidades múltiplas de utilização. A indústria nacional da aviação, por exemplo, é marcada pelo impulso conjunto: comercial-militar. Parte dessa trajetória, para fins elucidativos, é apresentada a seguir.

\section{A Indústria da Aviação no Brasil e o caso "Embraer"}

A criação do, então, "Ministério da Aeronáutica," em 20 de janeiro de 1941, teve a função explícita de ampliar o "desenvolvimento alcançado pela aviação nacional," e levava em consideração que a eficiência e o aparelhamento aeronáutico "são decisivos para o progresso e segurança nacionais” (Câmara dos Deputados, 1941:1.022).

Em 1946, com o término da Segunda Guerra Mundial, o Brasil teve auxílio direto do Massachusetts Institute of Technology (MIT) para planejar e desenvolver a própria indústria de aeronáutica (Centro Histórico da Embraer, 2012). Desse modo, em 1950, foi criado, no âmbito militar, o Instituto Tecnológico de Aeronáutica (ITA), a fim de formar engenheiros e técnicos, necessários ao Brasil, tanto na esfera da Defesa, quanto na comercial (Câmara dos Deputados, 1950:1).

A Empresa Brasileira de Aeronáutica S.A. (Embraer) foi instituída em 1969 (Câmara dos Deputados, 1938:20315). Seu impulso era diretamente governamental, destinada, inicialmente, à fabricação em série do avião Bandeirante - já, na época, concebido para uso tanto civil quanto militar (Centro Histórico da Embraer, 2012a).

Em 1981 a Embraer firmou acordo com as empresas italianas Aeritalia (atualmente Alenia) e Aermacchi "para o desenvolvimento e fabricação do AMX, um caça bombardeiro subsônico" (Centro Histórico da Embraer, 2012b). As tecnologias desenvolvidas para fins militares, nesse empreendimento, possibilitaram descobertas e inovações civis empregadas em projetos comerciais. O caso do projeto AMX não é único e nem raro na história de utilização dual na aviação brasileira, no entanto é apresentado como um exemplo exitoso pela ABIMDE (Gráfico 1). 


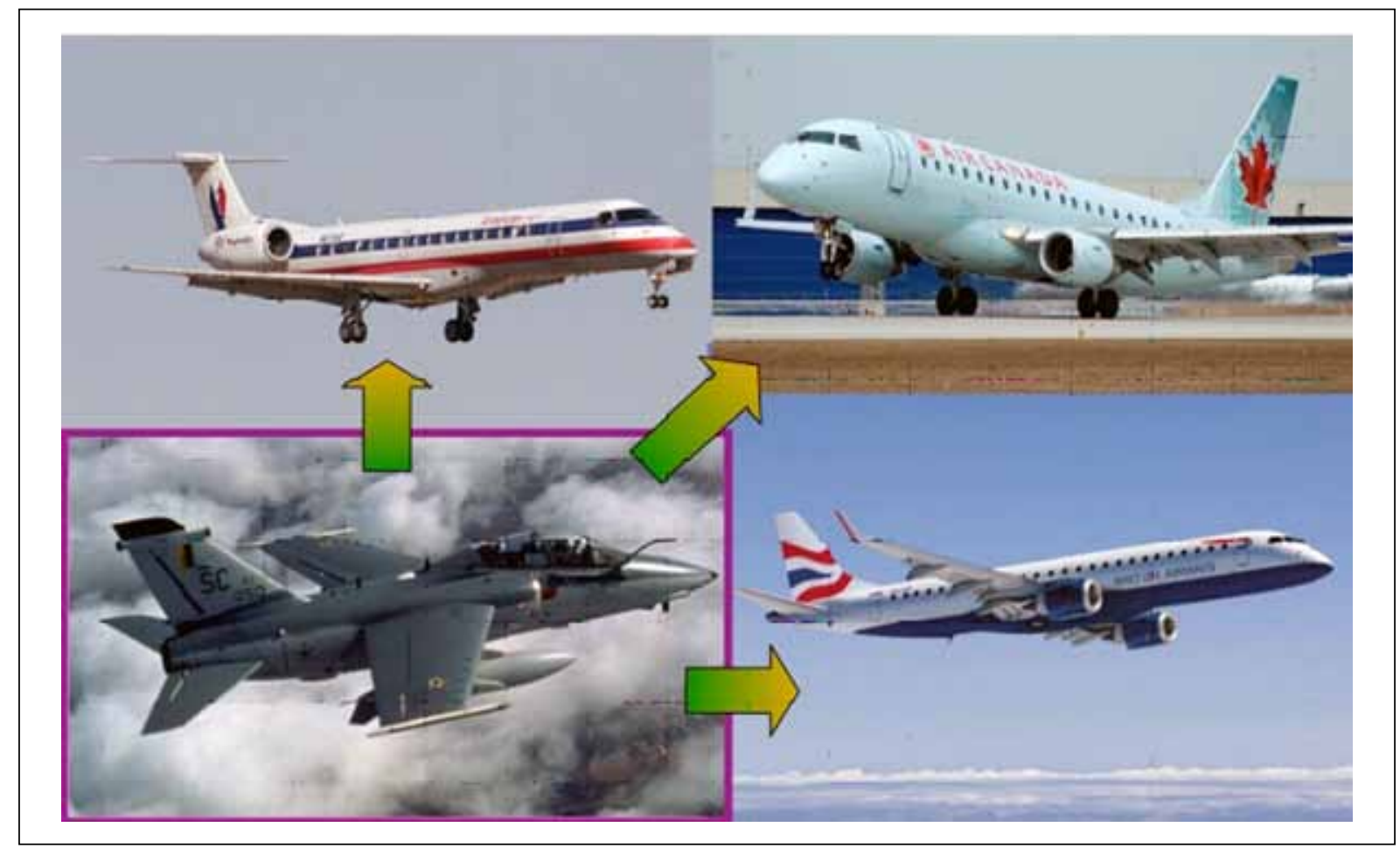

Fonte: ABIMDE (Moreira, 2011:36)

Ao longo de décadas a Embraer cresceu e se tornou uma das maiores empresas de fabricação de aviões do mundo. Em 1994 foi privatizada. Em 2011 foi a 81ano ranking mundial das empresas com maior venda de equipamentos de Defesa (Stockholm International Peace Research Institute, 2011). No mesmo ano ficou entre as cinco maiores receitas na venda de aviões comerciais (Flight International, 2012:36).

O desenvolvimento civil-militar no Brasil evidentemente não ocorre só na aviação e, nesse contexto, a Embraer é apenas um exemplo. Outro caso, bastante esclarecedor para os fins deste artigo é a construção do Submarino Nuclear Brasileiro. Neste caso, porém, destacam-se as dificuldades na aquisição de tecnologias estrangeiras para a produção nacional. Esse é o tema da próxima seção.

\section{Necessidade de desenvolvimento local de tecnologias: o Programa Nuclear da Marinha}

Antes de mais nada, cabe um esclarecimento: o Brasil é signatário do "Tratado Sobre a Não-Proliferação de Armas Nucleares” (TNP) (Comissão Nacional de Energia Nuclear, 2014), ou seja, o país não deseja desenvolver armas nucleares, tendo se submetido ao controle da "Agência Internacional de Energia Atômica" (AIEA). ${ }^{3}$

O projeto do submarino nuclear é, portanto, concernente à sua propulsão (conforme apresentado no Gráfico 2). Esta, por sua vez, apresenta vantagens sobre outras formas, como, por exemplo, a elétrica (que precisa de carga frequente) e a diesel (que, além da limitação da recarga, necessita de emersão para entrada do oxigênio empregado na queima do combustível).

30 Tratado, por sua vez, insere-se na Constituição Federal: "os direitos e garantias expressos nesta Constituição não excluem outros decorrentes do regime e princípios por ela adotados, ou dos tratados internacionais em que a República Federativa do Brasil seja parte” (Brasil, 1988, Art. $5^{0}, \S 2^{\circ}$ ). 


\section{NSTALAÇÃO PROPULSORA}

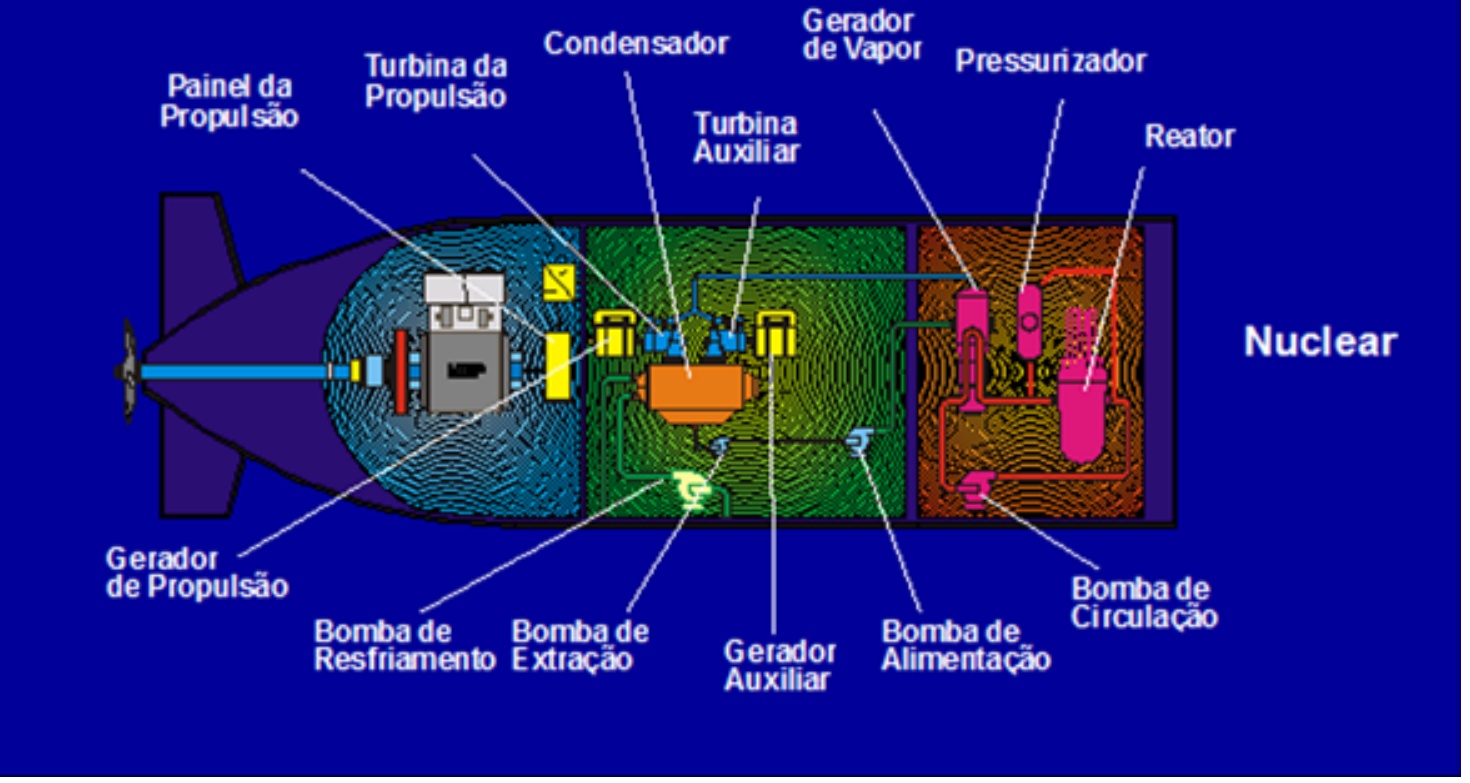

Fonte: Marinha do Brasil (Centro Tecnológico da Marinha em São Paulo, 2011:14)

O Programa Nuclear da Marinha começou a ser desenvolvido em 1979 e deve se estender até 2031 (Ministério da Defesa, 2013:1). Trata-se de um dos poucos programas de Estado para a Defesa Brasileira, tendo já permeado décadas e atravessado diferentes governos.

De acordo com a Marinha do Brasil, o Programa Nuclear compreende: “1. O desenvolvimento do Ciclo do Combustível; 2. O desenvolvimento de geração de energia núcleo-elétrica” (Centro Tecnológico da Marinha em São Paulo, 2011:3). Desse modo, os objetivos são: a construção de submarinos de propulsão nuclear e o desenvolvimento de tecnologias duais de geração de energia.

De qualquer forma, como demonstrado nos documentos a seguir, o Brasil vem tentando comprar no exterior algumas tecnologias necessárias ao submarino. Entretanto, apesar de expressamente ter se recusado a desenvolver armas nucleares e possuir os recursos necessários à aquisição, o país é constantemente impedido, pois a tecnologia nuclear possui cerceamentos internacionais, que vão das negativas de transferência da tecnologia às recusas de fornecimento (Centro Tecnológico da Marinha em São Paulo, 2011:4). 


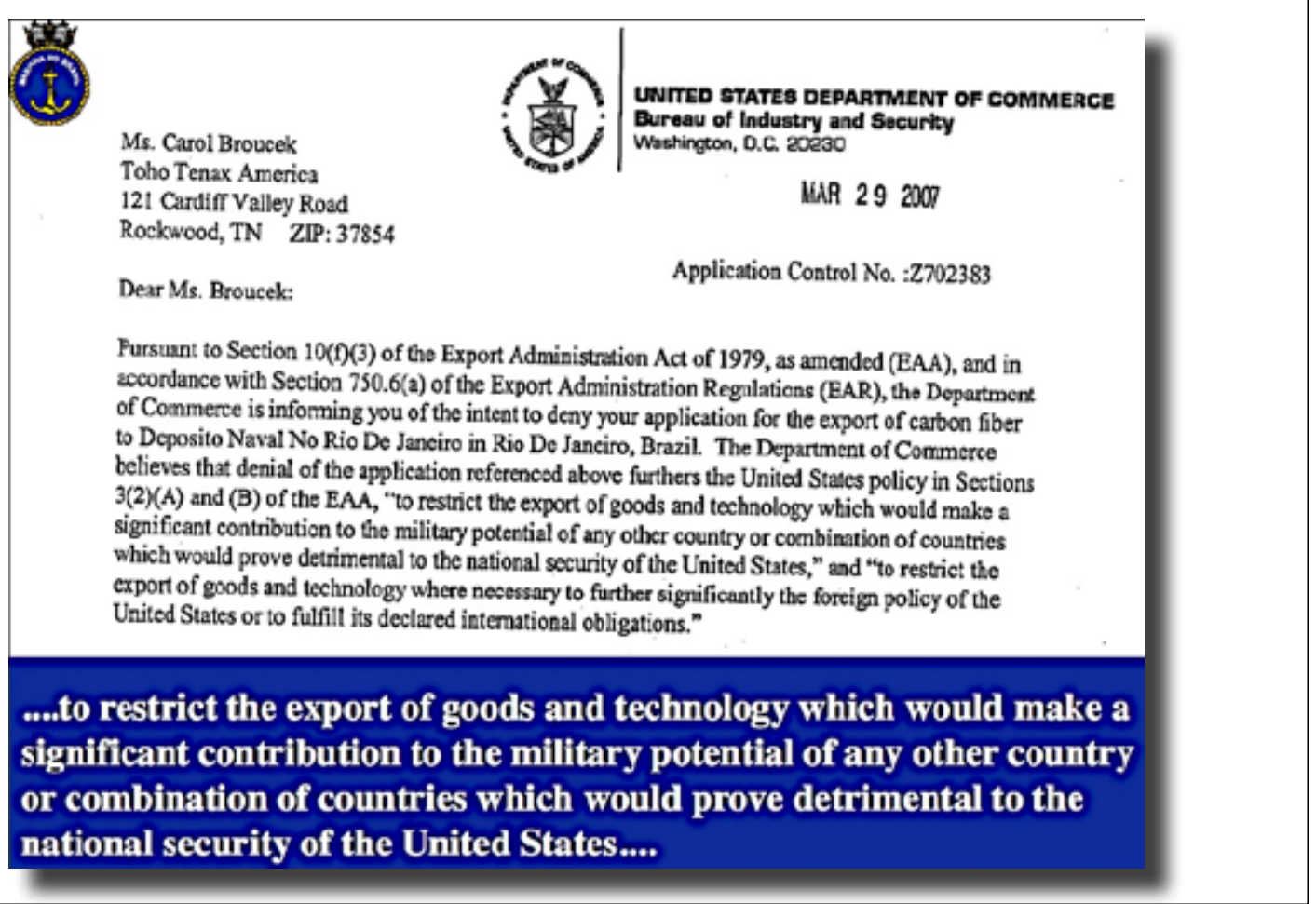

Fonte: Marinha do Brasil (Centro Tecnológico da Marinha em São Paulo, 2011:5)

O Documento 1 é o primeiro exemplo de negativa de repassar tecnologias (filtros de carbono utilizados em rotores de centrífugas nucleares) para a Marinha do Brasil. Neste caso, a proibição é do Departamento de Comércio dos Estados Unidos, em face à empresa "Toho Tenax America, Inc.", com o argumento de proteger a segurança nacional dos EUA perante "qualquer outro país ou combinação de países”. Uma situação similar ocorre no Documento 2:

Documento 2

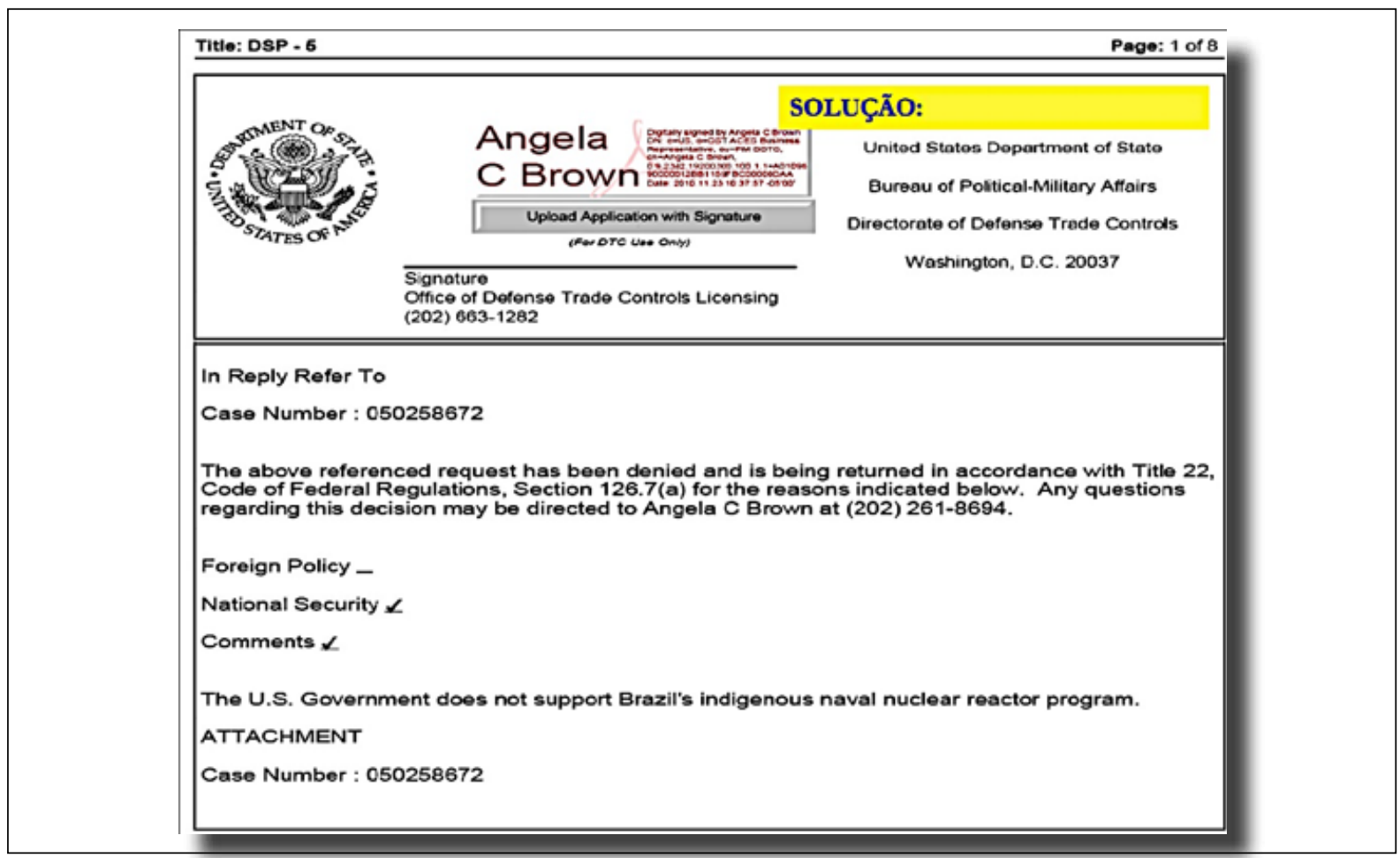

Fonte: Marinha do Brasil (Centro Tecnológico da Marinha em São Paulo, 2011:6) 
Note-se que, no Documento 2, consta a declaração direta de que "O governo dos Estados Unidos não apoia o programa de reator nuclear naval ‘nativo' do Brasil”.

Já o Documento 3, do Departamento do Comércio dos Estados Unidos, deixa claro que a Marinha do Brasil deve se submeter ao governo estadunidense na utilização estrita da tecnologia que o Brasil almeja comprar (no caso, o mesmo filtro de carbono).

Documento 3

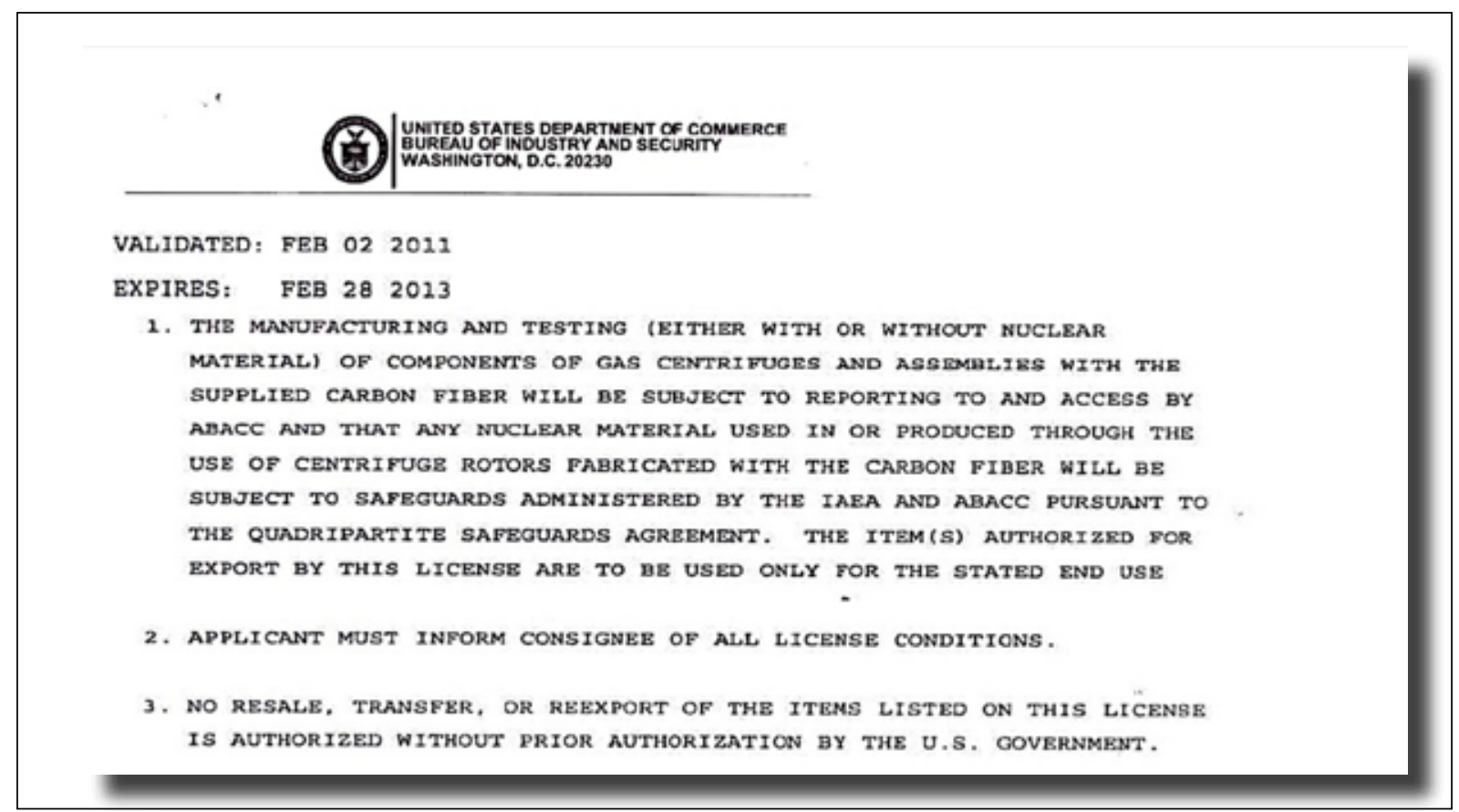

Fonte: Marinha do Brasil (Centro Tecnológico da Marinha em São Paulo, 2011:7)

Vale destacar, diante dos documentos apresentados, que o Brasil firmou um acordo de cooperação com a França, em dezembro de 2008 (Brasil, 2008:2-8), para a produção de submarinos. ${ }^{4}$ Embora o Documento 1 seja anterior ao acordo, o Documento 3 é posterior, abrindo a questão: se o acordo foi com a França, por que o Brasil continuou tentando comprar tecnologias dos Estados Unidos? ${ }^{5}$

Seja como for, mesmo quando consegue adquirir tecnologias para a realização de projetos, o Brasil sofre barreiras internacionais. Este é o caso do lançamento de satélites na base de Alcântara, já que 90\% das peças utilizadas nos equipamentos são patenteadas e fabricadas pelos Estados Unidos. Por isso, o Brasil é impedido de lançar e utilizar comercialmente a sua própria base.

4 “(...) Brasil e França firmaram, em 2008, um acordo que deu início ao PROSUB - Programa de Desenvolvimento de Submarinos. Esse programa viabilizará a produção do primeiro submarino brasileiro de propulsão nuclear e de mais quatro submarinos convencionais diesel-elétrico" (Marinha do Brasil, 2011:7). Disponível em: <www.marinha.mil.br/sites/default/files/imagens/banner_publicidade/prosub.pdf>. Acesso em 30 jan. 2014.

5 Justificativas para 0 acordo: SENADO FEDERAL (Brasil). Acordo Brasil-França. Brasília, D.F.: Comissão de Relações Exteriores e Defesa Nacional, 2011. pp. 9-12 (Opção pela França). Disponível em: <www.senado.gov.br/comissoes/cre/ap/AP2090916_Acordo_Brasil_Franca.pdf>. Acesso em 30 jan. 2014. 


\section{Entraves no setor aeroespacial}

Em 2006 os governos do Brasil e da Ucrânia (ex-integrante da República Soviética) se uniram na criação da "Alcântara Cyclone Space" (ACS), uma empresa pública binacional, com capital de ambos os países, para desenvolver tecnologia aeroespacial (Alcântara Cyclone Space, 2014). O objetivo seria explorar comercialmente a colocação em órbita de satélites, lançando-os com o foguete ucraniano Cyclone-4, a partir de Alcântara (no Maranhão), além de promover a transferência de tecnologia (Agência Espacial Brasileira, 2009).

A vantagem da base brasileira é a sua localização, na linha do Equador, o que possibilita a economia de combustível nos lançamentos. Contudo, cerca de $90 \%$ dos satélites em atividade possuem componentes provenientes dos Estados Unidos e a ACS não possui autorização para lançá-los. Isso ocorre porque o Brasil e os Estados Unidos não possuem acordo de salvaguarda tecnológica:

\footnotetext{
Historicamente, os EUA apresentam profundas restrições ao programa de lançadores do Brasil, uma vez que seus componentes têm uso duplo: civil e militar, ou seja, servem a foguetes e mísseis. Paradoxalmente, os EUA reconhecem Alcântara como excelente local para lançamentos, inclusive, de seus próprios foguetes. (Maltchik, O Globo, 6 jan. 2013)
}

Fica claro, assim, que, mesmo com vantagens geográficas, fins expressamente pacíficos, recursos e interesse em se autodesenvolver, o Brasil tem sido barrado por depender de tecnologias estrangeiras. A conclusão evidente é que desenvolver, o máximo possível, as próprias tecnologias, mais do que uma opção, é uma necessidade para qualquer nação que preze pelo seu futuro.

\section{Outros casos de entraves}

O míssil tático MAR-1, para utilização contra sistemas de defesa antiaérea baseados em terra ou plataformas marítimas, recebeu entraves dos Estados Unidos (quanto à plataforma girométrica e à cabeça de comando) (Moreira, 2011:50). O argumento dos EUA é de que "essa tecnologia excede o nível de capacidade aprovado para o Brasil”, conforme demonstra do Documento 4: 


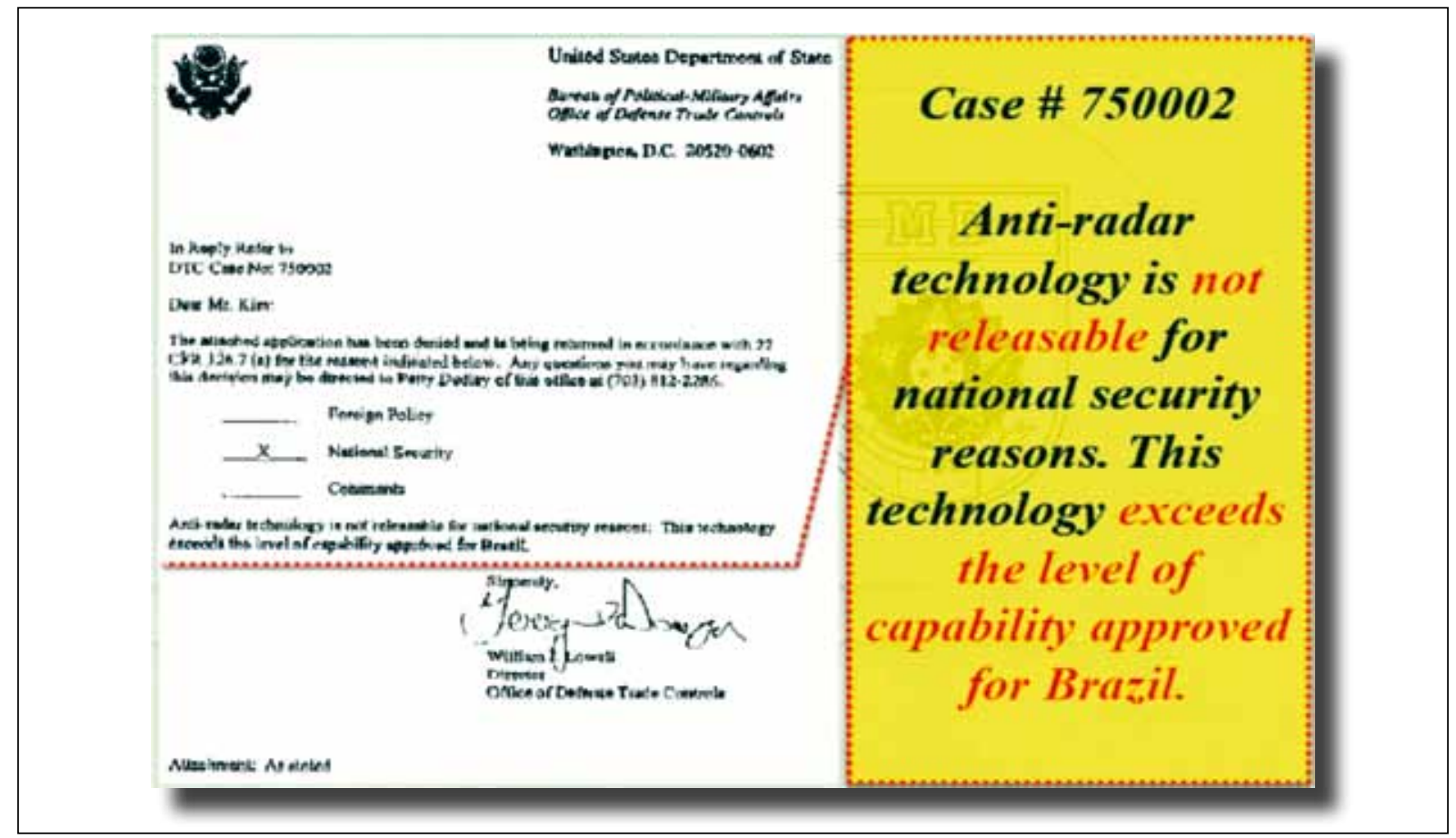

Fonte: ABIMDE (Moreira, 2011:49)

Os casos apresentados estão longe de ser exaustivos e apenas ilustram o fato de que "em assuntos estratégicos, a transferência de tecnologia é pouco comum” (Moreira, 2011:47).

As situações vão desde embargos ao enriquecimento de urânio por ultracentrifugação para fins pacíficos (Moreira, 2011:55) até o não repasse de informações sobre equipamentos comprados pelo Brasil, como ocorreu com o caça supersônico F-5, sobre o qual os EUA não forneceram dados de ensaio/modelo, dificultando a transferência de tecnologia (Moreira, 2011:51).

\section{O Brasil possui estrutura para a geração local de tecnologias civis e militares}

Há mais de 200 empresas-membro da Associação Brasileira das Indústrias de Materiais de Defesa e Segurança (ABIMDE). ${ }^{6}$ Dentre estas, destacam-se algumas tradicionais, como a Embraer, ${ }^{7}$ a Taurus, a CBC, a Odebrecht Defesa e Tecnologia, a IBCA e a Condor Tecnologias Não-Letais. As políticas de inovação na área devem levar em conta que a ABIMDE "atua no relacionamento entre as indústrias e os órgãos governamentais” (ABIMDE, 2014) do Brasil, e sua missão é, justamente, contribuir:

(...) na formulação de políticas públicas para o setor de Defesa, e para a criação e manutenção de uma Base Industrial, Logística, Científica, Tecnológica \& Inovação forte e saudável, voltadas para a Defesa, em consonância com os objetivos de soberania nacional e da Constituição Brasileira. (ABIMDE, 2014, grifos nossos)

\footnotetext{
6 ASSOCIAÇÃO BRASILEIRA DAS INDÚSTRIAS DE MATERIAIS DE DEFESA E SEGURANÇA. Associadas. São Paulo: ABIMDE, 2014. Disponível em: $<$ www.abimde.org.br/?on=associados > . Acesso em 30 jan. 2014.

7 "Em 19 de agosto de 1969 foi criada a Embraer - Empresa Brasileira de Aeronáutica, companhia de capital misto e controle estatal. Com 0 apoio do Governo Brasileiro, a Empresa iria transformar ciência e tecnologia em engenharia e capacidade industrial" (Empresa Brasileira de Aeronáutica, 2011. Disponível em: <www.embraer.com/pt-BR/ConhecaEmbraer/TradicaoHistoria/Paginas/Home.aspx>. Acesso em 30 jan. 2014). "A Embraer fabrica aviões comerciais, executivos, agrícolas e militares. Ao lado da canadense Bombardier, é a terceira maior produtora mundial de jatos civis, atrás da Airbus e da Boeing" (Senado Federal, 2011a. Disponível em: <www12.senado.gov.br/jornal/edicoes/2011/08/17/senadores-homenageiamembraer>. Acesso em 30 jan. 2014).
} 
A ABIMDE também publica cartilhas denominadas "Medidas viabilizadoras", nas quais lista sugestões de ações a serem tomadas "pelo governo, pelo Legislativo, pelos militares e pela sociedade em geral" (ABIMDE, 2011:5). O intuito de tais publicações se aproxima do proposto no presente estudo, ou seja: unir "esforços da Academia, Institutos de Ciência e Tecnologia, Indústrias de Base e Empresas Estratégicas de Defesa” para o fornecimento de "produtos e serviços garantidores de nossa soberania” (ABIMDE, 2011:3).

Além disso, há ainda outras empresas e indústrias que atuam com Defesa no Brasil e que não são associadas da ABIMDE, mas que, por razões econômicas inerentes, têm interesse em melhorias na base industrial de Defesa.

Portanto, a iniciativa privada do Brasil é, tanto expressamente, quanto tacitamente, favorável às políticas de incentivo à inovação científica e tecnológica, de acordo com os interesses do Brasil.

O país também dispõe da Associação Brasileira de Estudos de Defesa (ABED) - “uma sociedade acadêmica civil sem fins lucrativos que congrega professores e pesquisadores voltados para os estudos das instituições militares, políticas de Defesa e temas estratégicos” (ABED, 2014).

Há, ainda, interesse da Agência Brasileira de Desenvolvimento Industrial (ABDI) em compreender e desenvolver as empresas da área, conforme demonstra o convênio firmado em 2013 com o Instituto de Pesquisa Econômica Aplicada (IPEA) (IPEA, 2013).

Complementarmente, o potencial acadêmico, de universidades e pesquisadores é expressivo. Mesmo levando-se em consideração apenas os cursos de pós-graduação stricto sensu, como Mestrado e Doutorado, os números são substanciais, como pode ser observado na Tabela 2.

Somam-se, desta forma, 5.560 cursos de pós-graduação no Brasil, oferecendo potencial para modelos de inovação tecnológicas que contemplem também a Defesa. Em 2005, 2008 e com republicação em 2013, por exemplo, foi realizada uma iniciativa de expressiva receptividade com a comunidade acadêmica nessa área: o Programa Pró-Defesa (CAPES, 2013).

Tabela 2

Cursos de Pós-graduação por Região do Brasil

\begin{tabular}{|c|c|c|c|c|c|c|c|c|c|}
\hline \multicolumn{10}{|c|}{ Nota: TODOS } \\
\hline \multirow{2}{*}{ Região } & \multicolumn{5}{|c|}{ Programas e Cursos de pós-graduação } & \multicolumn{4}{|c|}{ Totais de Cursos de pós-graduação } \\
\hline & Total & M & D & $\mathbf{F}$ & M/D & Total & M & D & $\mathbf{F}$ \\
\hline Centro-0este & 304 & 141 & 7 & 37 & 119 & 423 & 260 & 126 & 37 \\
\hline Nordeste & 735 & 355 & 16 & 97 & 267 & 1.002 & 622 & 283 & 97 \\
\hline Norte & 197 & 102 & 4 & 33 & 58 & 255 & 160 & 62 & 33 \\
\hline Sudeste & 1.728 & 418 & 26 & 285 & 999 & 2.727 & 1.417 & 1.025 & 285 \\
\hline Sul & 777 & 277 & 6 & 118 & 376 & 1.153 & 653 & 382 & 118 \\
\hline Brasil & 3.741 & 1.293 & 59 & 570 & 1.819 & 5.560 & 3.112 & 1.878 & 570 \\
\hline
\end{tabular}

Legenda: M - Mestrado Acadêmico; D - Doutorado; F - Mestrado Profissional; M/D - Mestrado Acadêmico/Doutorado. Fonte: CAPES, 2014.

Possuindo tal estrutura acadêmica, o Brasil tem se mantido entre os 15 países com maior produção científica, de acordo com dados da Base Scopus (Thomson Reuters report). ${ }^{8}$ Em 2012 a produção brasileira ficou na 13ª posição, como pode ser observado na Tabela 3.

8 "Este relatório também indica que, em relação ao resto do mundo, o Brasil tem desempenho excepcionalmente bom em Biologia e disciplinas biomédicas, sendo responsável por 18,4\% da produção científica mundial em Medicina tropical com base na análise de 10.500 revistas científicas" (Hommaa; Possas et al, 2013:B54-B60. Disponível em: <www.sciencedirect.com/science/article/pii/S0264410X12017355>. Acesso em 30 jan. 2014. 
Tabela 3

Produção científica por país - 2012

\begin{tabular}{|c|c|c|c|c|c|c|c|}
\hline \multicolumn{2}{|r|}{ País } & \multirow{2}{*}{$\begin{array}{r}\text { Documentos } \\
537.308\end{array}$} & \multirow{2}{*}{$\begin{array}{r}\begin{array}{c}\text { Documentos } \\
\text { Citáveis }\end{array} \\
493.337\end{array}$} & \multirow{2}{*}{$\begin{array}{l}\text { Citações } \\
341.608\end{array}$} & \multirow{2}{*}{$\begin{array}{l}\text { Auto-Citações } \\
194.260\end{array}$} & \multirow{2}{*}{$\begin{array}{r}\begin{array}{l}\text { Citações por } \\
\text { Documentos }\end{array} \\
0,64\end{array}$} & \multirow{2}{*}{$\begin{array}{r}\text { H. Index } \\
1.380\end{array}$} \\
\hline 1 & Estados Unidos & & & & & & \\
\hline 2 & China & 392.164 & 383.117 & 105.523 & 62.551 & 0,27 & 385 \\
\hline 3 & Reino Unido & 152.877 & 137.413 & 106.306 & 36.218 & 0,7 & 851 \\
\hline 4 & Alemanha & 143.284 & 132.505 & 95.320 & 35.540 & 0,67 & 740 \\
\hline 5 & Japão & 118.768 & 111.893 & 50.816 & 18.510 & 0,43 & 635 \\
\hline 6 & França & 102.474 & 95.534 & 61.977 & 19.797 & 0,6 & 681 \\
\hline 7 & Índia & 98.081 & 91.366 & 25.665 & 11.829 & 0,26 & 301 \\
\hline 8 & Itália & 85.027 & 77.747 & 54.621 & 18.813 & 0,64 & 588 \\
\hline 9 & Canadá & 84.990 & 79.017 & 54.256 & 15.560 & 0,64 & 658 \\
\hline 10 & Espanha & 76.699 & 70.539 & 44.019 & 13.993 & 0,57 & 476 \\
\hline 11 & Coréia do Sul & 67.688 & 64.581 & 26.804 & 8.260 & 0,4 & 333 \\
\hline 12 & Austrália & 67.584 & 62.200 & 43.082 & 14.118 & 0,64 & 514 \\
\hline 13 & Brasil & 55.803 & 53.083 & 17.580 & 6.465 & 0,32 & 305 \\
\hline 14 & Holanda & 48.918 & 44.801 & 41.366 & 10.325 & 0,85 & 576 \\
\hline 15 & Taiwan & 40.387 & 38.493 & 16.059 & 4.932 & 0,4 & 267 \\
\hline 16 & Fed. Russa & 39.766 & 37.568 & 12.503 & 4.501 & 0,31 & 325 \\
\hline 17 & Irã & 39.384 & 37.384 & 10.007 & 4.913 & 0,25 & 135 \\
\hline 18 & Suíça & 36.042 & 33.513 & 33.732 & 8.120 & 0,94 & 569 \\
\hline 19 & Turquia & 33.911 & 31.323 & 10.938 & 3.631 & 0,32 & 210 \\
\hline 20 & Polônia & 31.948 & 30.666 & 13.850 & 4.723 & 0,43 & 302 \\
\hline
\end{tabular}

Aliás, sobre a produção acadêmica na área, o Livro Branco de Defesa Nacional é enfático:

Reforçou-se a consciência de que o país não é imune aos riscos e ameaças inerentes às relações entre estados, favorecendo-se o sentido de unidade dos pesquisadores que trabalhavam isolados. Desse modo, novas disciplinas foram criadas nos cursos de relações internacionais e ciência política, e instituíram-se cursos específicos sobre defesa. (Ministério da Defesa, 2013:182)

Demonstra-se, desta forma, que:

1. Há interesse do Ministério da Defesa em reestruturar o seu modelo de inovação, unindo governo, indústrias e universidades (conforme a Estratégica Nacional de Defesa);

2. Ao mesmo tempo, as indústrias de material bélico do Brasil contêm tal motivação (expressa na missão da ABIMDE);

3. E que projetos envolvendo a Defesa foram agraciados recentemente no meio acadêmico do país (Programa Pró-Defesa), além de multiplicaram-se programas de estudo na área (de acordo com o Livro Branco de Defesa Nacional).

Delineia-se, assim, a existência, no Brasil, de indústrias e universidades, cujos empreendedores e pesquisadores estão dispostos a interagir e a buscar a produção de ciência e tecnologia, tanto militar, quanto civil.

Nesse contexto, o Rio de Janeiro possui um papel de destaque, conforme será abordado a seguir.

\section{A contribuição do Rio de Janeiro na geração de tecnologias de usos múltiplos}

Das 210 associadas da ABIMDE, 48 têm sede no Rio de Janeiro. Trata-se do segundo Estado do Brasil com o maior número de empresas nesse setor, atrás, apenas, de São Paulo (Gráfico 3).

116 - Cadernos do Desenvolvimento Fluminense, Rio de Janeiro, N.7, pp. 105 - 124, jan./jun. 2015 
Gráfico 3

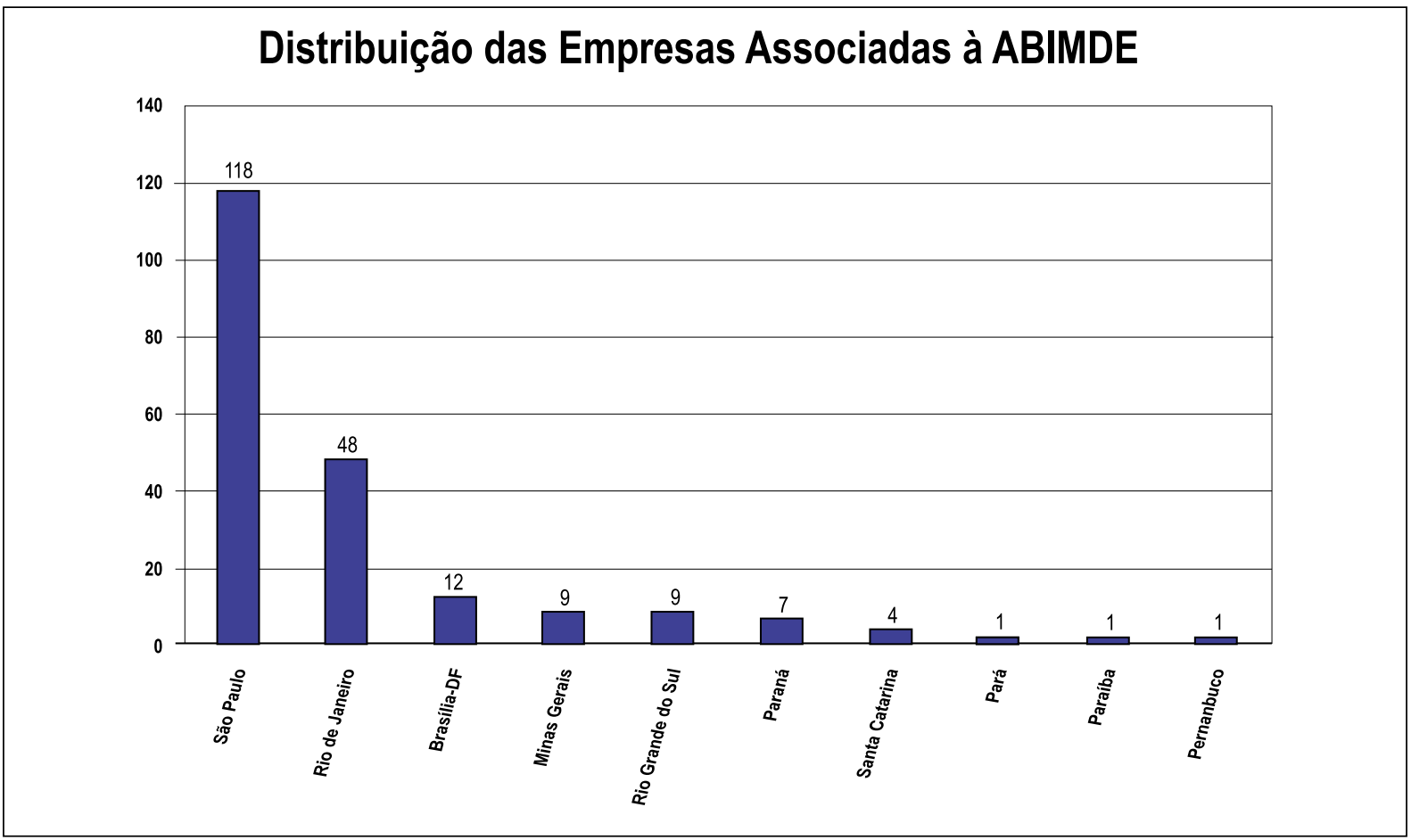

Fonte: Elaboração própria com dados da ABIMDE (2014)

Quanto ao potencial acadêmico, para realização pesquisas que possam ser utilizadas pelas indústrias, o Estado do Rio de Janeiro possui 690 cursos de pós-graduação stricto sensu:

Tabela 4

Cursos de Pós-graduação no Estado do Rio de Janeiro (continua)

\begin{tabular}{|c|c|c|c|c|}
\hline Instituição de Ensino Superior & $\begin{array}{l}\text { Mestrado } \\
\text { Profissional }\end{array}$ & Mestrado & Doutorado & Total \\
\hline ASSOC. INST. NACIONAL DE MATEMÁTICA PURA E APLICADA - IMPA & 1 & 1 & 1 & 3 \\
\hline CENTRO BRASILEIRO DE ESTUDOS LATINO-AMERICANOS - CEBELA & 0 & 1 & 0 & 1 \\
\hline CENTRO BRASILEIRO DE PESQUISAS FÍSICAS - CBPF & 1 & 1 & 1 & 3 \\
\hline CENTRO FED. EDUC. TECN. CELSO SUCKOW DA FONSECA - CEFET/RJ & 1 & 5 & 1 & 7 \\
\hline CENTRO UNIVERSITÁRIO AUGUSTO MOTTA - UNISUAM & 1 & 1 & 0 & 2 \\
\hline CENTRO UNIVERSITÁRIO DE VOLTA REDONDA - UniFOA & 2 & 0 & 0 & 2 \\
\hline CENTRO UNIVERSITÁRIO ESTADUAL DA ZONA OESTE - UEZO & 1 & 0 & 0 & 1 \\
\hline CENTRO UNIVERSITARIO PLINIO LEITE - UNIPLI & 1 & 0 & 0 & 1 \\
\hline COLÉGIO PEDRO ॥ - CPII & 1 & 0 & 0 & 1 \\
\hline ESCOLA DE COMANDO E ESTADO-MAIOR DO EXÉRCITO - ECEME & 0 & 1 & 0 & 1 \\
\hline ESCOLA DE GUERRA NAVAL - EGN & 1 & 0 & 0 & 1 \\
\hline ESCOLA NACIONAL DE CIÊNCIAS ESTATÍSTICAS - ENCE & 0 & 1 & 0 & 1 \\
\hline FACULDADE DE ECONOMIA E FINANÇAS DO IBMEC - IBMEC & 2 & 0 & 0 & 2 \\
\hline FUNDAÇÃO CESGRANRIO - CESGRANRIO & 1 & 0 & 0 & 1 \\
\hline FUNDAÇÃO GETÚLIO VARGAS/RJ - FGV/RJ & 4 & 5 & 3 & 12 \\
\hline FUNDAÇÃO OSWALDO CRUZ - FIOCRUZ & 10 & 18 & 18 & 46 \\
\hline INST. NAC. METROLOGIA, NORM. E QUALIDADE IND. - INMETRO & 1 & 1 & 1 & 3 \\
\hline INST. DE ENGENHARIA NUCLEAR - IEN & 1 & 1 & 0 & 2 \\
\hline INST. DE PESQUISAS JARDIM BOTANICO DO RIO DE JANEIRO - JBRJ & 1 & 1 & 1 & 3 \\
\hline INST. DE RADIOPROTEÇÃO E DOSIMETRIA - IRD & 0 & 1 & 1 & 2 \\
\hline INST. DO PATRIMÔNIO HISTÓRICO E ARTÍSTICO NACIONAL - IPHAN & 1 & 0 & 0 & 1 \\
\hline INST. FED. DE EDUC., CIÊNCIA E TECNOL. DO RIO DE JANEIRO - IFRJ & 2 & 1 & 0 & 3 \\
\hline INST. FED. DE EDUCAÇÃO, CIÊNCIA E TECNOLOGIA FLUMINENSE - IFF & 1 & 0 & 0 & 1 \\
\hline INST. MILITAR DE ENGENHARIA - IME & 0 & 8 & 3 & 11 \\
\hline
\end{tabular}




\begin{tabular}{|c|c|c|c|c|}
\hline Instituição de Ensino Superior & $\begin{array}{l}\text { Mestrado } \\
\text { Profissional }\end{array}$ & Mestrado & Doutorado & Total \\
\hline INST. NACIONAL DA PROPRIEDADE INDUSTRIAL - INPI & 1 & 0 & 1 & 2 \\
\hline INST. NACIONAL DE CÂNCER - INCA & 0 & 1 & 1 & 2 \\
\hline INST. NACIONAL DE CARDIOLOGIA - INC & 2 & 0 & 0 & 2 \\
\hline INST. NACIONAL DE TRAUMATOLOGIA E ORTOPEDIA - INTO & 1 & 0 & 0 & 1 \\
\hline LABORATÓRIO NACIONAL DE COMPUTAÇÃO CIÊNTÍFICA - LNCC & 0 & 1 & 1 & 2 \\
\hline OBSERVATÓRIO NACIONAL - ON & 0 & 2 & 2 & 4 \\
\hline PONTIFÍCIA UNIVERSIDADE CATÓLICA DO RIO DE JANEIRO - PUC-RIO & 3 & 27 & 24 & 54 \\
\hline SOCIEDADE BRASILEIRA DE MATEMÁTICA - SBM & 1 & 0 & 0 & 1 \\
\hline UNIVERSIDADE CÂNDIDO MENDES - UCAM & 3 & 4 & 2 & 9 \\
\hline UNIVERSIDADE CATÓLICA DE PETRÓPOLIS - UCP/RJ & 1 & 3 & 1 & 5 \\
\hline UNIVERSIDADE DA FORÇA AÉREA - UNIFA & 1 & 0 & 0 & 1 \\
\hline UNIVERSIDADE DO ESTADO DO RIO DE JANEIRO - UERJ & 4 & 47 & 37 & 88 \\
\hline UNIV. DO GRANDE RIO - PROF JOSE DE SOUZA HERDY - UNIGRANRIO & 2 & 2 & 1 & 5 \\
\hline UNIVERSIDADE ESTÁCIO DE SÁ - UNESA & 2 & 3 & 3 & 8 \\
\hline UNIV. ESTADUAL DO NORTE FLUMINENSE DARCY RIBEIRO - UENF & 0 & 13 & 10 & 23 \\
\hline UNIVERSIDADE FEDERAL DO ESTADO DO RIO DE JANEIRO - UNIRIO & 7 & 13 & 7 & 27 \\
\hline UNIVERSIDADE FEDERAL DO RIO DE JANEIRO - UFRJ & 15 & 92 & 86 & 193 \\
\hline UNIVERSIDADE FEDERAL FLUMINENSE - UFF & 13 & 55 & 35 & 103 \\
\hline UNIVERSIDADE FEDERAL RURAL DO RIO DE JANEIRO - UFRRJ & 3 & 22 & 12 & 37 \\
\hline UNIVERSIDADE SALGADO DE OLIVEIRA - UNIVERSO & 0 & 3 & 1 & 4 \\
\hline UNIVERSIDADE SEVERINO SOMBRA - USS & 2 & 1 & 0 & 3 \\
\hline UNIVERSIDADE VEIGA DE ALMEIDA - UVA & 4 & 0 & 1 & 5 \\
\hline TOTAL & 99 & 336 & 255 & 690 \\
\hline
\end{tabular}

Fonte: CAPES, 2014a.

O Estado também é sede de importantes centros de pesquisa das Forças Armadas, como o Instituto Militar de Engenharia (IME), a Universidade da Força Aérea (UNIFA), a Escola de Guerra Naval (EGN) e a Escola Superior de Guerra (ESG).

Além disso, pesquisadores da Universidade Federal Fluminense e da Universidade Federal do Rio de Janeiro tradicionalmente têm participado de projetos com aporte financeiro do Pró-Defesa, deixando claro o interesse acadêmico pelos temas relacionados à Defesa Nacional.

\section{Considerações prévias}

As referências bibliográficas citadas - algumas oriundas de publicações do próprio Ministério da Defesa - evidenciam que, com raras exceções, ao longo das últimas décadas, as políticas de Defesa adotadas pelos governos do Brasil não visaram, na prática, a produção e domínio de tecnologias nacionais de vanguarda.

Complementarmente, cabe aqui salientar que, em 17 de dezembro de 2008, pela primeira vez na história do Brasil, foi publicada uma Estratégia Nacional de Defesa (já mencionada no presente artigo). Esse documento norteador, atualizado em 2012, dispõe:

(...) reorganização da Base Industrial de Defesa, para assegurar que o atendimento às necessidades de tais produtos por parte das Forças Armadas apoie-se em tecnologias sob domínio nacional, preferencialmente as de emprego dual (militar e civil). (Brasil, 2013:10, grifos nossos)

118 - Cadernos do Desenvolvimento Fluminense, Rio de Janeiro, N.7, pp. 105 - 124, jan./jun. 2015 
Ao longo do documento, além da reafirmação da necessidade de tecnologias de domínio nacional, desponta a questão da independência pela capacitação:

\begin{abstract}
Independência nacional alcançada pela capacitação tecnológica autônoma, inclusive nos estratégicos setores espacial, cibernético e nuclear. Não é independente quem não tem o domínio das tecnologias sensíveis, tanto para a defesa, como para o desenvolvimento. (Brasil, 2013:2, grifos nossos)
\end{abstract}

A Estratégia Nacional de Defesa de 2008 perfaz um diagnóstico das 16 principais vulnerabilidades da estrutura de Defesa do Brasil, das quais destacam-se as seguintes:

7. Limitados recursos aplicados em pesquisa científica e tecnológica para o desenvolvimento de material de emprego militar e produtos de defesa, associados ao incipiente nível de integração entre os órgãos militares de pesquisa, e entre estes e os institutos civis de pesquisa;

8. Inexistência de planejamento nacional para desenvolvimento de produtos de elevado conteúdo tecnológico, com participação coordenada dos centros de pesquisa das universidades, das Forças Armadas e da indústria;

14. Bloqueios tecnológicos impostos por países desenvolvidos, retardando os projetos estratégicos de concepção brasileira. (Brasil, 2013:32 e 33, grifos nossos)

Para fins de ênfase, na citação acima foram grifadas expressões nos itens selecionados (7, 8 e 14) que, por serem reconhecidos como vulnerabilidades na própria Estratégia de Defesa, denotam o quanto pode ser oportuno - e, em certa medida, até necessário - para os objetivos do Brasil no cenário internacional desenvolver uma integração militar-industrialacadêmica. ${ }^{9}$ Tal fato, aliás, é evidenciado na referida estratégia, na forma de "oportunidades a serem exploradas":

- otimização dos esforços em Ciência, Tecnologia e Inovação para a Defesa, por intermédio, dentre outras, das seguintes medidas:

(a) maior integração entre as instituições científicas e tecnológicas, tanto militares como civis, e a Base Industrial de Defesa;

(b) definição de pesquisas de uso dual; e

(c) fomento à pesquisa e ao desenvolvimento de produtos de interesse da defesa.

- maior integração entre as indústrias estatal e privada de produtos de defesa, com a definição de um modelo de participação na produção nacional de meios de defesa. (Brasil, 2013:27, grifos nossos)

Isso posto, embora seja notório que não está sólida a conexão entre a academia e as indústrias no Brasil, também é evidente que o país e o Rio de Janeiro possuem estrutura para a geração local de tecnologias de usos múltiplos. A ponderação, portanto, não poderia ser outra: é preciso avançar em termos de planejamento e integração, a fim de formalizar parcerias público-privadas.

\title{
Conclusão
}

Há tecnologias militares absolutamente necessárias, mesmo para nações com relativamente pouca tradição bélica e, se não forem produzidas, terão que ser compradas no exterior, como tem acontecido no Brasil ao longo de décadas.

É preciso, no entanto, que haja planejamento e integração, para que não ocorram casos como a aquisição dos tanques Gepard, em 2013, na última hora, para a vinda do Papa ao

90 modelo teve como principal formulador: BUSH, Vannevar. Science The Endless Frontier: A Report to the President by Vannevar Bush, Director of the Office of Scientific Research and Development. Washington: United States Government Printing Office, 1945. Dwight Eisenhower criou a expressão complexo "industrial-militar", que foi reconhecida pelo Senador William Fulbright, como um "complexo militar-industrial-acadêmico": SHILLER, Herbert I. \& PHILLIPS, Joseph D. (eds.). Super-state: readings in the military-industrial complex. Urbana: University of Illinois Press, 1970. p. 171-178. 
Brasil e a Copa das Confederações. Neste caso, as tecnologias - tanques usados com chassi da década de 1960 para emprego como artilharia antiaérea - foram especialmente recauchutados pela fabricante alemã Krauss-Maffei Wegmann e vendidas ao Brasil (Stochero, G1, 11 abr. 2013).

Do ponto de vista brasileiro, produzir tecnologias internamente é vantajoso, pois as indústrias geram empregos, inovações e bens de consumo, enquanto que as universidades geram ciência e, também, inovações. Em outras palavras: o país se desenvolve nesse processo. Do ponto de vista do Rio de Janeiro, produzir tecnologias dentro do Estado também é vantajoso, e pelos mesmos motivos.

O Rio de Janeiro possui diferenciais estratégicos, por sua localização junto ao mar e por já possuir uma estrutura pronta para ser melhor empregada, como as referidas indústrias, os centros de pesquisa das Forças Armadas e as universidades com os seus respectivos pesquisadores. A proximidade com São Paulo, onde está concentrado o maior número de indústrias de Defesa, também é um diferencial para o Rio de Janeiro. Isso porque, para além de se pensar nas vantagens de uma base industrial e de pesquisa, é preciso que se delineie o desenvolvimento do país em conjunto, de forma cooperada.

Nesse sentido, embora ainda timidamente diante do potencial que possui, e com processos decisórios que chegam a se arrastar por décadas, o Brasil tem se movimentado para aproveitar melhor a própria estrutura industrial. Por exemplo, na aquisição do caça Gripen $N G$, da empresa sueca $S a a b$, após quase duas décadas de negociações, o governo optou pela proposta que permite ao país ter participação conjunta no desenvolvimento do projeto, contemplando empresas nacionais - como a Embraer - e mão de obra local (a previsão é de que sejam gerados 5,8 mil empregos direitos na região de São Bernardo do Campo, em São Paulo) (Globo, G1, 2014). De fato, ter direitos sobre a propriedade intelectual foi um fator determinante no acordo que preteriu os franceses (da Dassault, com o caça Rafale) e os estadunidenses (da Boeing, com o caça F-18 Super Hornet) (Monteiro, O Estado de S. Paulo, 20 dez. 2013).

Certamente o país e cada um de seus estados têm muito a se beneficiar da produção local. Os governos federal, estadual e, mesmo municipal, têm, por isso, a importante tarefa de estimular as parcerias entre universidades e indústrias, conforme previsto na Estratégia Nacional de Defesa (Brasil, 2013:24), dando preferência ao desenvolvimento planejado de tecnologias nacionais em detrimento da mera compra internacional.

Se o mercado for atrativo, as indústrias irão, naturalmente, produzir pesquisa aplicada e equipamentos. Por outro lado, as universidades têm a crucial tarefa de produzir a pesquisa básica - e, por vezes, também aplicada - que desencadeará em novas soluções científicas. Da tripla hélice entre governo, indústrias e universidades, aliás, resulta a fórmula que tem sido empregada por países como Estados Unidos (Leslie, 1993:2 e 6), Coreia do Sul e Israel há décadas. Diante de tal perspectiva, cabe ao Brasil e ao Rio de Janeiro planejamento e integração.

A opção de ser um mero consumidor ou um produtor de tecnologias de usos múltiplos se apresenta diante do Brasil. Para que o país se desenvolva, basta que se opte pelo desenvolvimento nacional planejado e de longo prazo - que nada mais é que o papel do governo. Soluções imediatistas e tomadas na urgência da necessidade atrasam o desenvolvimento e mantêm a nação dependente do conhecimento e de tecnologias estrangeiras. Por conseguinte, a escolha pelo desenvolvimento local precisa ser implementada em escala progressivamente maior. Essa, por sua vez, é uma responsabilidade de toda a sociedade, afinal, como é próprio 
das democracias, as Forças Armadas respondem aos representantes eleitos - e estes se submetem, diretamente, à população que os elegeu.

\section{Referências bibliográficas}

AGÊNCIA ESPACIAL BRASILEIRA (Ministério da Ciência, Tecnologia e Inovação). Governo do Maranhão e Alcântara Cyclone Space acertam MA-106. Brasília, D.F.: AEB, 2009. Disponível em: <www.aeb.gov.br/2008/08/governo-do-maranhao-e-alcantara-cyclone-space-acertamreconstrucao-da-ma-106> . Acesso em 30 jan. 2014.

ALCÂNTARA CYCLONE SPACE. Company. Brasília, D.F.: ACS, 2014. Disponível em: <www. alcantaracyclonespace.com/about/company >. Acesso em 30 jan. 2014.

AMARANTE, José Albano do. Indústria Brasileira de Defesa: Uma questão de soberania e de autodeterminação. In: PINTO, J. R. de Almeida; ROCHA, A. J. Ramalho da; SILVA, R. Doring Pinho da. (Orgs.), Pensamento Brasileiro sobre Defesa e Segurança. As Forças Armadas e o desenvolvimento científico e tecnológico do país. (Vol. 3). Brasília: Ministério da Defesa, 2004 .

ASSOCIAÇÃO BRASILEIRA DAS INDÚSTRIAS DE MATERIAIS DE DEFESA E SEGURANÇA. Associadas. São Paulo: ABIMDE, 2014. Disponível em: <www.abimde.org. br/?on=associados $>$. Acesso em 30 jan. 2014.

. Home. São Paulo: ABIMDE. Disponível em: <www.abimde.org.br>. Acesso em 30 jan. 2014.

. Medidas viabilizadoras. São Paulo: ABIMDE, out. 2011.

ASSOCIAÇÃO BRASILEIRA DE ESTUDOS DE DEFESA. Bem-vindo à ABED. Niterói: ABED, 2014. Disponível em: <www.abedef.org>. Acesso em 30 jan. 2014.

BRASIL. Acordo entre o Governo da República Federativa do Brasil e o Governo da República Francesa na Área de Submarinos. Brasília, D.F.: Governo Federal, 2008. Disponível em: $<$ www.senado.gov.br/atividade/Materia/getPDF.asp?t=86940\&tp=1>. Acesso em 30 jan. 2014.

. Constituição (1988). Constituição da República Federativa do Brasil: promulgada em 5 de outubro de 1988. Brasília: Palácio do Planalto. Art. 142. Disponível em: <www.planalto. gov.br/ccivil_03/constituicao/constituicao.htm>. Acesso em 30 jan. 2014.

. Estratégia Nacional de Defesa. [2008, 2012]. Brasília: Diário Oficial da União, República Federativa do Brasil, Imprensa Nacional, 26 set. 2013. No 187, p. 1. Decreto Legislativo $\mathrm{N}^{\circ}$ 373 de 2013. Disponível em: <www.defesa.gov.br/arquivos/2012/mes07/end.pdf>. Acesso em: 30 jan. 2014.

BUSH, Vannevar. Science The Endless Frontier: A Report to the President by Vannevar Bush, Director of the Office of Scientific Research and Development. Washington: United States Government Printing Office, 1945.

CÂMARA DOS DEPUTADOS (Brasil). Decreto Lei No 2961, de 20 de Janeiro de 1941: Exposição de Motivos. Brasília, D.F.: Diário Oficial da União, Seção 1, 20 jan 1941. p 1.022 [Publicação 
original]. Disponível em: <www2.camara.leg.br/legin/fed/declei/1940-1949/decreto-lei2961-20-janeiro-1941-412859-publicacaooriginal-1-pe.html>. Acesso em 30 jan. 2014.

. Decreto $N^{o}$ 27.695, de 16 de Janeiro de 1950 (Definido pela Lei No 2.165 de 05 de janeiro de 1954). Brasília, D.F.: Diário Oficial da União, Seção 1, 17 jan. 1950. p. 1 [Publicação original]. Disponível em: <www2.camara.leg.br/legin/fed/decret/1950-1959/decreto-2769516-janeiro-1950-322400-publicacaooriginal-1-pe.html>. Acesso em 30 jan. 2014.

Decreto-Lei $n^{o}$ 770, de 6 de Outubro de 1938. Brasília, D.F.: Diário Oficial da União, Seção 1, 8 out. 1938. p. 20315 [Publicação original]. Disponível em: <www2.camara.leg.br/ legin/fed/declei/1930-1939/decreto-lei-770-6-outubro-1938-350277-publicacaooriginal-1-pe. html>. Acesso em 30 jan. 2014.

CARDOSO, Alberto Mendes. O papel da ciência e tecnologia na Defesa e Soberania Nacional. In: PINTO, J. R. de Almeida; ROCHA, A. J. Ramalho da; SILVA, R. Doring Pinho da. (Orgs.), Pensamento Brasileiro sobre Defesa e Segurança. As Forças Armadas e o desenvolvimento científico e tecnológico do País. Brasília: Ministério da Defesa, 2001. Vol. 3.

CENTRO HISTÓRICO DA EMBRAER. Linha do Tempo: Eventos antes da Embraer. São José dos Campos: Embraer, 2012. Acesso digital: <www.centrohistoricoembraer.com.br/sites/ timeline/pt-BR/Paginas/default.aspx\#todos/antes>. Acesso em 30 jan. 2014.

. Linha do Tempo: Eventos de 60’s. São José dos Campos: Embraer, 2012a. Disponível em: <www.centrohistoricoembraer.com.br/sites/timeline/pt-BR/Paginas/default. aspx\#todos/1960>. Acesso em 30 jan. 2014.

. Linha do Tempo: Eventos de 80’s. São José dos Campos: Embraer, 2012b. Disponível em: <www.centrohistoricoembraer.com.br/sites/timeline/pt-BR/Paginas/default. aspx\#todos/1980>. Acesso em 30 jan. 2014.

CENTRO TECNOLÓGICO DA MARINHA EM SÃO PAULO (Marinha do Brasil). Painel 4: Índice de Nacionalização dos Produtos de Defesa. In: XI ENCONTRO NACIONAL DE ESTUDOS ESTRATÉGICOS - Rio de Janeiro: Escola Naval, 16-18 nov. 2011.

COMISSÃO NACIONAL DE ENERGIA NUCLEAR (Ministério da Ciência, Tecnologia e Inovação). Tratado Sobre a Não-Proliferação de Armas Nucleares. Brasília, D.F.: CNEN, 2014. Disponível em: <www.cnen.gov.br/Doc/pdf/Tratados/TRAT0001.pdf>. Acesso em 30 jan. 2014.

COORDENAÇÃO DE APERFEIÇOAMENTO DE PESSOAL DE NÍVEL SUPERIOR (Ministério da Educação, Brasil). Programa de apoio ao ensino e à pesquisa científica e tecnológica em defesa nacional (Pró-Defesa). Brasília, D.F.: Capes, 2013. Disponível em: <www.capes.gov.br/ bolsas/programas-especiais/pro-defesa > . Acesso em 30 jan. 2014.

. Mestrados/Doutorados Reconhecidos. Brasília, D.F.: Capes, 2014. Disponível em: $<\mathrm{http}$ ://conteudoweb.capes.gov.br/conteudoweb/ProjetoRelacaoCursosServlet?acao=pesqui sarRegiao\&conceito=34567> . Acesso em 30 jan. 2014.

. Mestrados/Doutorados Reconhecidos: Região Sudeste. Brasília, D.F.: Capes, 2014a. Disponível em: <http://conteudoweb.capes.gov.br/conteudoweb/ProjetoRelacaoCursos Servlet acao $=$ pesquisarRegiaoIes $\&$ codigoRegiao $=3 \&$ descricaoRegiao $=$ Sudeste $\&$ concei to $=34567 \#>$. Acesso em 30 jan. 2014.

COUTO, Ronaldo Costa. Memória viva do regime militar - Brasil 1964-1985. Rio de Janeiro: Ed. Record, 1999. 
DEFESANET. Novo presidente da ABIMDE prevê crescimento no setor e um grande mapeamento da indústria de defesa brasileira. Brasília, D.F.: 31 jan. 2013. Disponível em: $<$ www.defesanet.com.br/bid/noticia/9516/ABIMDE---Assume-Sami-Hassuani>. Acesso em 30 jan. 2014.

DEPARTAMENTO DE PLANEJAMENTO, ORÇAMENTO E FINANÇAS (Ministério da Defesa, Brasil). Execução Orçamentária: Séries Estatísticas, 2000 - 2012. Disponível em: <www. defesa.gov.br/lai/images/despesas/serie_estatistica_1995_2012.pdf>. Acesso em 30 jan. 2014. EMPRESA BRASILEIRA DE AERONÁUTICA. Conheça a Embraer: Evolução. São José dos Campos: Embraer, 2011. Disponível em: <www.embraer.com/pt-BR/ConhecaEmbraer/ TradicaoHistoria/Paginas/Home.aspx>. Acesso em 30 jan. 2014.

EMPRESA SUECA DE CAÇAS vai instalar fábrica em São Bernardo, no ABC. Globo, São Paulo: G1, 2014. Disponível em: <http://g1.globo.com/sao-paulo/noticia/2013/12/empresasueca-de-cacas-vai-instalar-fabrica-em-sao-bernardo-no-abc.html>. Acesso em 30 jan. 2014.

FLIGHT INTERNATIONAL. Top 100 Special Report. Flightglobal.com: 18-24 Sep. 2012. Disponível em: <www.pwc.com/en_GX/gx/aerospace-defence/assets/pwc-aerospace-top100-companies-2012.pdf > . Acesso em 30 jan. 2014.

HOMMAA, Akira; POSSAS, Cristina et al. Vaccine research, development, and innovation in Brazil: A translational science perspective. Vaccine, Vol. 31, Supplement 2, 18 Apr. 2013. p. B54-B60. Disponível em: <www.sciencedirect.com/science/article/pii/ S0264410X12017355>. Acesso em 30 jan. 2014.

INSTITUTO DE PESQUISA ECONÔMICA APLICADA. Chamada Pública No 130/2013 - Projeto "Mapeamento da Base Industrial de Defesa." Brasília, D.F.: IPEA/ABDI, 2013. Disponível em: <www.ipea.gov.br/portal/images/stories/PDFs/131119_chamadapublica_pnpd130.pdf> Acesso em 30 jan. 2014.

LESLIE, Stuart. The Cold War and the American Science: The Military-Industrial-Academic Complex at MIT and Stanford. New York: Columbia University Press, 1993.

MALTCHIK, Roberto. Projeto de meio bilhão de reais para lançamento comercial de satélites está em xeque. O Globo, Rio de Janeiro, Ed. 6 jan. 2013. Disponível em: <http://oglobo.globo. com/pais/projeto-de-meio-bilhao-de-reais-para-lancamento-comercial-de-satelites-esta-emxeque-7210946>. Acesso em 30 jan. 2014.

MARINHA DO BRASIL. Programa de Desenvolvimento de Submarinos. Rio de Janeiro: PROSUB, 2011. Disponível em: <www.marinha.mil.br/sites/default/files/imagens/banner_ publicidade/prosub.pdf>. Acesso em 30 jan. 2014.

MINISTÉRIO DA DEFESA (Brasil). Livro Branco de Defesa Nacional. [2012]. Brasília: Diário Oficial da União, República Federativa do Brasil, Imprensa Nacional, 26 set. 2013. № 187, p. 1. Decreto Legislativo No 373 de 2013. Disponível em: <www.defesa.gov.br/arquivos/2012/ mes07/lbdn.pdf>. Acesso em 30 jan. 2014.

MOLAS-GALLART, Jordi. Dual use technologies and the different transfer mechanisms. University of Sussex, Falmer, Brighton, CoPS Publication, n. 55, 1998. Disponível em: <www. cops.ac.uk/pdf/cpn55.pdf>. Acesso em: 30 jan. 2014.

MONTEIRO, Tânia. 'Propriedade intelectual sobre aeronave foi determinante', diz 
comandante. O Estado de S. Paulo, São Paulo, 20 dez. 2013. Disponível em: <www.estadao. com.br/noticias/impresso,propriedade-intelectual-sobre-aeronave-foi-determinante-dizcomandante,1110733,0.htm>. Acesso em 30 jan. 2014.

MOREIRA, Claudio. Associação Brasileira das Indústrias de Materiais de Defesa e Segurança Segurança. Brasília: D.F.: Comissão de Relações Exteriores e Defesa Nacional (Senado Federal, Brasil), 17 out. 2011 (últimos dados disponíveis: 2009). Disponível em: <www.senado.leg. br/comissoes/cre/ap/AP20111003_Claudio_Moreira.pdf>. Acesso em 30 jan. 2014.

. Associação Brasileira das Indústrias de Materiais de Defesa e Segurança Segurança. Brasília: D.F.: Comissão de Relações Exteriores e Defesa Nacional (Senado Federal, Brasil), 17 out. 2011. Disponível em: <www.senado.leg.br/comissoes/cre/ap/AP20111003_Claudio_ Moreira.pdf $>$. Acesso em 30 jan. 2014.

SECRETARIA DE ORÇAMENTO FEDERAL (Ministério do Planejamento, Orçamento e Gestão, Brasil). Orçamento Federal ao Alcance de Todos, Projeto de Lei Orçamentária Anual - PLOA 2012. Brasília, D.F.: PLOA 2012. Disponível em: <www.planejamento.gov.br/secretarias/ upload/Arquivos/sof/ploa2012/110831_orc_fed_alc_todos.pdf> . Acesso em 30 jan. 2014.

SENADO FEDERAL (Brasil). Acordo Brasil-França. Brasília, D.F.: Comissão de Relações Exteriores e Defesa Nacional, 2011. Disponível em: <www.senado.gov.br/comissoes/cre/ap/ AP2090916_Acordo_Brasil_Franca.pdf>. Acesso em 30 jan. 2014.

. Senadores homenageiam Embraer. Jornal do Senado, Brasília, D.F., 17 ago. 2011a. Disponível em: <www12.senado.gov.br/jornal/edicoes/2011/08/17/senadores-homenageiamembraer $>$. Acesso em 30 jan. 2014.

SHILLER, Herbert I.; PHILLIPS, Joseph D. (eds.). Super-state: readings in the militaryindustrial complex. Urbana: University of Illinois Press, 1970.

SMITH, Roe M. Military Enterprise and Technological Change. Cambridge, Mass: The MIT Press, 1985.

STOCHERO, Tahiane. Brasil compra arma antiaérea para Copa das Confederações e Papa. Globo, São Paulo: G1, 11 abr. 2013. Disponível em: <http://g1.globo.com/brasil/ noticia/2013/04/brasil-compra-artilharia-para-copa-das-confederacoes-e-visita-do-papa. html>. Acesso em $1^{\circ}$ fev 2014.

STOCKHOLM INTERNATIONAL PEACE RESEARCH INSTITUTE. The SIPRI Top 100 armsproducing and military services companies in the world excluding China, 2011. Stockholm: SIPRI, 2011. Disponível em: <www.sipri.org/research/armaments/production/Top100>. Acesso em 30 jan. 2014.

THE SCIMAGO JOURNAL. Country Rankings. Madrid: Scimago Lab, Data Source Scopus, 2012. Disponível em: <www.scimagojr.com/countryrank.php?area $=0 \&$ category $=0$ \&region $=$ all\&year $=2012 \&$ order $=i t \& \min =0 \&$ min_type $=i t>$. Acesso em 30 jan. 2014.

copyright (C) Cccreative Brommons Brustolin 